\title{
O Conceito Schenkeriano de "Organicidade" e a Sonata K533 de Mozart
}

\author{
Guilherme Sauerbronn de $\operatorname{Barros}^{1}$ e Cristina Capparelli Gerling ${ }^{2}$
}

A obra de Schenker convida a uma reflexão histórica sobre o apogeu do pensamento tonal e sua relação com as técnicas de contraponto. Embora prioritariamente associado ao pensamento harmônico funcional, o repertório tonal requer para sua interpretação uma compreensão dos processos contrapontísticos empregados para apresentar, manter e resolver as dissonâncias em vários níveis. Portanto, desconsiderar o contraponto presente nas obras do alto classicismo significa traduzir uma língua sem o conhecimento dos códigos apropriados e pode acarretar a perda da vitalidade original, improvisatória, deste repertório. Os artigos que examinaremos a seguir fazem parte do segundo volume do anuário Das Meisterwerk in der Musik, (1926) e serão acompanhados de uma reflexão histórica sobre a sonata K533 de Mozart.

\section{1 - A Organicidade na Forma Sonata (Vom Organischen der Sonatenform)}

"um poema ou mesmo uma outra obra de arte resulta da Idéia do todo e não pode ser composta de uma maneira meramente atomística." (Schlegel, Philosofie der Sprache und des Wortes. KA, XVIII, P.367-368 in Suzuki, 1998, p.205)

No início do artigo sobre A Organicidade na Forma Sonata, Schenker é categórico:

\begin{abstract}
"Ao conceito de forma sonata, conforme os teóricos ensinaram até hoje, falta precisamente o principal - a noção de organicidade - que determina o surgimento das vozes a partir da unidade da tríade fundamental, i.e., o desdobramento da Urlinie e o arpejamento do baixo. A percepção desta característica do acorde fundamental é privilégio dos gênios, que a Natureza graciosamente lhes concedeu. (...) Tal sentimento não pode ser alimentado artificialmente; em outras palavras, somente a criatividade baseada na improvisação pode garantir a unidade do processo composicional. Portanto, o conceito de forma sonata, para fazer jus ao geral, deve incluir o seguinte: o todo deve originar-se da
\end{abstract}

\footnotetext{
${ }^{1}$ Professor do Departamento de Música do Ceart e Orientador do projeto de Pesquisa "Procedimentos analíticos e princípios filosóficos: uma avaliação crítica da obra de Heinqich Schenker

${ }^{2}$ Professora do Departamento de Música do Ceart e participante do Projeto de Pesquisa
}

DAPesquisa, Florianópolis, v.2, n.4, p. 491-499, 2007. 
improvisação, caso contrário trata-se apenas de uma mera colagem de partes independentes e motivos, segundo um conjunto de regras." ${ }^{3}$

Nesta passagem deparamos com o conceito de improvisação, ao qual Schenker recorre para explicar o modo segundo o qual a forma orgânica brota das mãos do gênio ${ }^{4}$. Este conceito não deve ser compreendido meramente no sentido corrente, como "improviso", i.e., criação e execução simultâneas de uma peça. Não, em Schenker este termo adquire um significado profundo e diz respeito à composição musical segundo os princípios universais da estrutura fundamental - em oposição à simples obediência a regras criadas artificialmente.

\section{1 - O gênio e a organicidade da arte}

Conforme ensinou Kant, o gênio é a faculdade através da qual a natureza fornece as regras à arte e "consiste, propriamente, num feliz acordo entre a imaginação e o entendimento, que nenhuma ciência pode explicar, que não se pode adqüirir mediante nenhum ofício.” (C.J., §49) Portanto, Kant apenas aponta para o processo, mas não pode explicá-lo efetivamente. O mesmo ocorre com Schenker: "Eu não me atreveria a explicar como a inspiração chega até o gênio, a declarar com certeza qual porção do nível intermediário ou do nível externo se apresenta primeiro à sua imaginação: os derradeiros segredos permanecerão eternamente inacessíveis para nós." ${ }^{5}$

Diante da impossibilidade de expor positivamente a mágica da criação artística, Schenker caracteriza o modus operandi do gênio como improvisação. No artigo sobre a forma sonata, no qual examina a Sonata em Gm Hob XVI, Schenker descreve Haydn: "A linha fundamental [Urlinie] e o arpejamento do baixo [Bassbrechung] governavam-no com um poder instintivo, e, a partir deles, desenvolveu uma engenhosa capacidade para criar ${ }^{3}$ Schenker, Heinrich, The Masterwork in Music, v.2, New York: Cambridge University Press, 1996, p.23, grifo nosso

${ }^{4}$ Schenker, assim como os românticos, aprendeu a "lição kantiana que liga gênio e totalidade orgânica." (Suzuki, Marcio. O Gênio Romântico - Crítica e História da Filosofia em Friedrich Schlegel, São Paulo: Iluminuras, 1998, p.6)

${ }^{5}$ Schenker, Heinrich. Free Composition (Der Freie Satz) - Volume III of New Musical Theories and Fantasies, 2 v., New York: Longman Inc., 1979, p.9 
tensão ao longo de uma obra, como se esta fosse uma entidade. ${ }^{6}$ Após demonstrar que o primeiro e o segundo temas da sonata, apesar das diferenças superficiais, foram construídos sobre estruturas análogas - arpejamentos do baixo em processo imitativo - Schenker pergunta: "poderia Haydn ter desenvolvido esses dois arpejamentos sem um impulso improvisatório a mostrar-lhe o caminho? (...) Onde, na obra de um não gênio, poderíamos encontrar tal poder de coesão, semelhante arpejamento que conecta diversos elementos da forma em um só todo?"7

\section{2 - O Intérprete e a Improvisação}

Schenker confere à interpretação a importante função de comunicar o conteúdo da obra: "Terá, alguma vez, uma interpretação desta sonata impresso este milagre em nossos corações?" ${ }^{8} \mathrm{O}$ "milagre" da organicidade do todo e das partes, deve, portanto, ser revelado na interpretação, apresentação (expositio) da obra.

Porém, para que isso ocorra, é necessária uma participação intensa do intérprete e um uso genial de sua criatividade:

"Mas, para conceber algo [a nível de interpretação] que se equipare ao plano mais elevado da criatividade musical, é necessário o conceito de um espírito genial que, criado secretamente a partir do nível fundamental de uma Ursatz, domina todos os arpejos dos muitos acordes individuais e todas as diminuições das progressões lineares.

E ainda assim, obviamente, esta interpretação da idéia do compositor é apenas eventualmente satisfatória: uma obra musical aparece, para o leitor ou executante, apenas como nível externo, e este é, por assim dizer, análogo ao presente e à vida cotidiana. Assim como é geralmente difícil compeender o significado de um evento no presente se não tivermos consciência do seu background no passado, assim também é difícil para um executante ou leitor compreender o presente de uma obra musical sem ter consciência do seu nível fundamental. Assim como as exigências do dia-a-dia empurram-no ora para um lado ora para o outro, o nível externo de uma obra musical faz o mesmo com ele: a cada mudança de acorde, a cada diminuição, cromatismo ou nota vizinha, tudo lhe parece novo e cada novidade o afasta para longe da coerência do nível fundamental." ${ }^{9}$

\footnotetext{
${ }^{6}$ ibid, p.24

${ }^{7}$ ibid, pp. 24 e 25

${ }^{8}$ Schenker, 1996, p.27

${ }^{9}$ Schenker, 1996, p.28
}

DAPesquisa, Florianópolis, v.2, n.4, p. 491-499, 2007. 
O intérprete que não é capaz de perceber o nível fundamental da obra e ainda não descobriu o seu próprio fundamento (background) é duramente criticado por Schenker: "Aqueles que buscam temas e melodias na sonata, como se buscassem momentos de prazer na vida, estão assumindo uma posição baseada num modo de vida vulgar da vida cotidiana. O leigo aspira por melodias em busca de gratificação imediata. (...)"10

Sua crítica se estende ainda aos teóricos de seu tempo: "A melodia, da maneira equivocada que a concebem o leigo e os teóricos, nasceu do estabelecimento das menores relações na arte; a sonata, em contrapartida, representa competência no maior dos mundos imagináveis no relacionamento tonal, na era de seu maior desenvolvimento." ${ }^{11}$

Os "motivos" e as células temáticas, extremamente importantes na visão de outros teóricos, são, para Schenker, resultado das "diminuições", cuja principal função é prolongar a estrutura fundamental.

\begin{abstract}
"As chamadas melodias, temas e motivos dos teóricos anteriores não apontam o caminho para a forma sonata. Aquilo que deveria ser compreendido como motivos-diminuições da forma sonata foi apresentado nos exemplos acima, juntamente com muitos outros. Estes consistem, independentemente do escopo da obra, em arpejamentos, acoplamento de oitavas e unidades em níveis mais altos, estabelecidas por repetição, como, por exemplo, as notas vizinhas [bordaduras] nas figuras 3 e 5 e nas figuras $4 \mathrm{~h}$ e $4 \mathrm{~g}$, e assim por diante. Porém, sem uma compreensão dos motivos neste sentido, o escopo e a abrangência da improvisação, a única capaz de criar coerência orgânica na forma sonata, jamais se realizaria." ${ }^{12}$
\end{abstract}

Portanto, o cerne da crítica de Schenker aos teóricos de seu tempo é justamente a ausência de gênio - e de improvisação - na obra desses autores. Não apenas as análises realizadas a partir das teorias correntes, mas as obras compostas segundo os tratados de composição convencionais são, na visão de Schenker, estruturas mortas, cadáveres desprovidos da chama vital que somente a verdadeira arte do gênio possui.

$\mathrm{O}$ artigo seguinte, sobre a organicidade da fuga, torna-se particularmente interessante se lido em conjunto com o anterior. Além de desenvolver o tema da

\footnotetext{
${ }^{10}$ ibid, p.29

${ }^{11} \mathrm{ibid}$

${ }^{12}$ ibid, pp. 29 e 30
}

DAPesquisa, Florianópolis, v.2, n.4, p. 491-499, 2007. 
organicidade em outro contexto, Schenker dá relevo à afinidade das formas musicais, uma vez que, tanto a fuga como a sonata compartilham um mesmo fundamento - o nível fundamental - e nascem através de um mesmo processo - a improvisação genial.

\section{2 - A Natureza Orgânica da Fuga como Demonstrado na Fuga em Dó menor do Cravo Bem Temperado de J.S. Bach, livro I (Das Organische der Fuge aufgezeigt an der I. C-Moll-Fugeaus dem Wohltemperierten Klavier von Joh. Seb. Bach)}

Se no artigo anterior Schenker não nomeava diretamente os teóricos que tanto criticava, neste artigo, ao contrário, os alvos de seus ataques estão todos claramente identificados: F.W. Marpurg (1718-1795), A.B. Marx e Hugo Riemann são os mais conhecidos; Wilhelm Werker, Wolfgang Graeser e Carl van Bruyck, completam o time.

$\mathrm{O}$ artigo começa com uma longa citação de Schumann. As atividades de compositor, editor musical, editor literário, a formação abrangente, que incluía de Jean Paul e Hoffman a Schlegel, conferem à produção crítica de Schumann brilho, profundidade e alcance dificilmente encontrados em outros autores.

O artigo de Schumann, sobre as fugas de Mendelssohn, trata justamente da distância existente entre as regras propostas pelos métodos escolásticos que ensinam a compor fugas, como o de Marpurg por exemplo, e aquilo que se pode verificar nas fugas de Bach. Schumann comenta ainda que obras criadas a partir desses métodos são caricaturas grotescas de uma arte que se perdeu no passado. Mendelssohn, entretanto, teria conseguido realizar algo menor, porém digno, em seus Prelúdios e Fugas op.35.

Schumann aponta três atitudes básicas diante das fugas: a primeira, é a do ouvinte que repudia essa forma, fugindo sempre que possível da execução deste tipo de obra; a outra é a do estudante de composição que se baseia nos tratados e, por conta disso, considera as fugas de Bach, Beethoven e Haendel imperfeitas porque demasiadamente livres; por fim, Schumann se confessa partidário de uma terceira atitude, a daqueles que se 
"deliciam por horas nas fugas de Bach, Beethoven, Haendel" ${ }^{13}$ e que não acreditam que, no presente, seja possível voltar a compor fugas.

Todavia, Schumann reconhece o valor relativo das fugas de Mendelssohn, que ele compara a singelas "flores", se consideradas ao lado das "florestas de carvalhos gigantes" que Bach cultivou. Schenker, aproveitando esta imagem, dirá que Marpurg, com sua visão estreita, baseada em regras artificiais, "não tem noção da 'flor' que Schumann viu." ${ }^{14}$ Ele diz ainda que a fuga, "assim como todas as outras formas de vida, segue seu próprio curso." 15 . A variedade de imagens orgânicas que Schenker utiliza é marcante: ele fala em "organismos fugais"16, explica que a "vida da tríade" ${ }^{17}$ decorre do desejo ou da necessidade desta manifestar sua vida na dimensão horizontal e aponta a existência de "harmonias naturais" que emergem do nível fundamental no momento da criação e das quais, por sua vez, brotam as melodias que ornamentam o nível externo ${ }^{18}$.

O foco de Schenker neste artigo, diferentemente do anterior, não está tanto no compositor que cria a partir da improvisação, mas na própria música enquanto entidade orgânica. A percepção da unidade viva que é uma fuga contrasta com outras interpretações analíticas:

"Como pode tal interpretação [a de Bruyck] e outras do mesmo tipo diferir tão absolutamente da minha? Será que a diferença está apenas na terminologia, ou estará para além desta ou daquela 'teoria' e depende de um modo completamente diferente de escuta? Um autor escuta três seções; eu, apenas uma. Outro ainda escuta notas vibrando, intensificação e efeito poético; eu ouço uma linguagem racional de sons, mais racional do que a própria linguagem falada. E, se aplicada à fala, poderá alguém conceber tal diferença nos modos de escuta? Deixo que o leitor tire suas próprias conclusões." ${ }^{19}$

\footnotetext{
${ }^{13}$ Schenker, 1996, p.31

${ }^{14}$ ibid, p. 32

${ }^{15} \mathrm{ibid}$

${ }^{16} \mathrm{ibid}$

${ }^{17}$ ibid, p.34

${ }^{18}$ ibid, p. 35

${ }^{19}$ ibid, p.53
}

DAPesquisa, Florianópolis, v.2, n.4, p. 491-499, 2007. 


\section{3 - Bach, Mozart e a Sonata K533}

Ao mudar-se para Viena Mozart renovou seu conhecimento com o Barão von Swieten ${ }^{20}$, médico da imperatriz. O barão, em suas visitas a Frederico da Prússia, trouxera muitos manuscritos do então olvidado Johann Sebastian Bach, entre estes o Cravo Bem Temperado. No final dos anos 1780, este músico amador organizou uma Sociedade de Associados ${ }^{21}$ para nobres amantes da música. Os encontros aconteciam com regularidade nas manhãs de domingo na biblioteca imperial de Viena e um quarteto de cordas, no qual Mozart tocava viola, apresentava transcrições encomendadas pelo Barão.

Enquanto transcrevia fugas de Bach, Mozart conheceu também a Arte da Fuga e a Oferenda Musical, além de obras para órgão. Visto que a maioria dos prelúdios cujas fugas o barão solicitava transcrições não se adaptavam à escrita para cordas, Mozart não só escreveu novos prelúdios, mas procurou ativamente estabelecer pontos de união entre os prelúdios e as fugas; suas transcrições, portanto, não são fiéis e contêm introduções. O resultado desta atividade assinala a integração entre o contraponto bachiano e a prática composicional do final do século $\mathrm{XVIII}^{22}$. O amálgama de recursos contrapontísticos, processos motívicos e a qualidade discursiva e dialogante das composições fornecem os elementos que definem o apogeu do estilo clássico. A partir do estudo das obras de Bach e Händel por Mozart e Haydn durante os anos 1780, passagens explicitamente contrapontísticas integram-se sem costuras ou emendas aparentes ao restante da trama musical, ou melhor dizendo, parecem ser a razão de ser dessas obras.

O processo composicional de Bach passa a ser estudado ou revivido por Mozart, conforme atesta a carta endereçada à irmã Constanze, na qual faz referência à composição da Fantasia e Fuga K.394: "Iniciei pela fuga e a escrevi enquanto pensava no prelúdio. Penso que só você poderá lê-la porque a escrita está tão miúda; espero ainda que goste. Da próxima vez vou enviar alguma coisa melhor para teclado" ${ }^{23}$. Mozart deixou inúmeras fugas para um e dois pianos inacabadas, que, segundo Alfred Einstein, não são obras

\footnotetext{
${ }^{20}$ Gottfried van Swieten (1733- 1803) , aristocrata, médico da Imperatriz da Áustria, exerceu funções diplomáticas junto a Frederico da Prússia e Augusto da Saxônia. Foi igualmente amigo de Beethoven.

${ }^{21}$ Gesellschaft der Associierten. Haydn também participava ativamente desta sociedade.

${ }^{22}$ Citamos como exemplo o fugato do Zauberflöte e o último movimento da sinfonia Júpiter.

${ }^{23}$ Mozart, Wolfgang Amadeus. Briefe, Berlin: Henschelverlag,1989, p. 292-293
} 
magistrais, mas estudos de composição ${ }^{24}$. De fato, nas sonatas para piano escritas em Viena podemos observar a profusão de processos contrapontísticos empregados.

Neste sentido, desejamos convidá-los a pensar que a língua musical falada por Bach é compartilhada ainda mais proximamente por Mozart a partir de sua mudança para Viena e que este compartilhamento torna-se evidente nos processos contrapontísticos amalgamados ao discurso musical. Ao transcrever as fugas, Mozart não comenta as diferenças estilísticas ou as décadas que o separam de seus predecessores, mas preenche esta lacuna com sua própria música, nos seus próprios termos. Afinal, a base tonal é exatamente a mesma, somente os artifícios mudaram.

É importante notar que, em certa medida, o pensamento polifônico já se encontra presente nas primeiras sonatas de Mozart, visto que o preenchimento da linha do baixo através de processos contrapontísticos constituía uma prática habitual ${ }^{25}$. Convém, no entanto, reparar na atmosfera mais grave, no contraponto mais explicita e sistematicamente trabalhado destas últimas obras: as amabilidades ficam reservadas para os rondós finais. Assim como qualquer compositor de sua época, Mozart internaliza e trabalha uma proporção harmônica de longo alcance, mas as partes são determinadas por elementos diretamente extraídos das práticas contrapontísticas. Se nas primeiras sonatas este trabalho infunde leveza e graciosidade, nas sonatas K 457, K 533, K 494 e K 570, encontramos um elevado nível de abstração e densidade. O frescor e a vitalidade destes processos composicionais retornam no seu aspecto mais linearizado na Sonata K 576.

Aludindo à invenção do classicismo, convém pensar que Mozart, retratado como o primeiro compositor romântico por E.T.A.Hoffman ${ }^{26}$, foi o primeiro de uma longa lista de compositores em busca de uma ligação com J.S.Bach e que, ao fazê-lo, produziram suas composições mais memoráveis como resultado deste diálogo atemporal.

\footnotetext{
${ }^{24}$ Einstein, Alfred. Mozart - His Character, His Work, Oxford University Press, 1945

${ }^{25}$ Como se sabe, Mozart, Haydn e Beethoven (para citar apenas os clássicos) estudaram contraponto segundo o método de Johann Joseph Fux. Em contrapartida, o estudo da harmonia como disciplina somente foi estabelecido no Conservatório de Paris no início do século XIX.

${ }^{26}$ Rosen, Charles. The Classical Style - Haydn, Mozart, Beethoven, New York: W.W. Norton \& Company, 1972, p. 19
} 


\section{4 - Conclusão}

O Allegro da Sonata K533 pode ser considerado praticamente uma "sonata-fuga" e traz à tona uma característica fundamental do pensamento schenkeriano: o pensamento tonal - que manifesta sua organicidade através da improvisação genial - está para além das barreiras formais e estilísticas; fuga e sonata representam o apogeu da forma em diferentes momentos (no início e no final do século XVIII), mas estão conectadas por um mesmo substrato tonal. Na sonata K533 “a natureza polifônica da fuga e a natureza homofônica da sonata" 27 encontram-se para dar vida a uma obra particularmente rica. Mozart, neste caso, não é apenas o gênio, mas o estudioso das obras de Bach.

\footnotetext{
${ }^{27}$ Adorno, T. W. Filosofia da Nova Música, São Paulo: Editora Perspectiva, 1989, p.50
}

DAPesquisa, Florianópolis, v.2, n.4, p. 491-499, 2007. 